\title{
Article \\ Effect of Selection for Pyrethroid Resistance on Abiotic Stress Tolerance in Aedes aegypti from Merida, Yucatan, Mexico
}

\author{
Keenan Amer ${ }^{1}$, Karla Saavedra-Rodriguez ${ }^{2}$, William C. Black IV ${ }^{2}$ and Emilie M. Gray ${ }^{1, *}$ \\ 1 Department of Organismal Biology \& Ecology, Colorado College, Colorado Springs, CO 80903, USA; \\ k_amer@coloradocollege.edu \\ 2 Department of Microbiology, Immunology \& Pathology, College of Veterinary Medicine and Biomedical \\ Sciences, Colorado State University, Fort Collins, CO 80523, USA; \\ karla.saavedra_rodriguez@colostate.edu (K.S.-R.); william.black@colostate.edu (W.C.B.IV) \\ * Correspondence: egray@coloradocollege.edu
}

Citation: Amer, K.

Saavedra-Rodriguez, K.; Black, W.C., IV; Gray, E.M. Effect of Selection for Pyrethroid Resistance on Abiotic Stress Tolerance in Aedes aegypti from Merida, Yucatan, Mexico. Insects 2021, 12, 124. https://doi.org/10.3390/ insects12020124

Academic Editor: Amanda Callaghan Received: 31 December 2020

Accepted: 28 January 2021

Published: 31 January 202

Publisher's Note: MDPI stays neutral with regard to jurisdictional claims in published maps and institutional affiliations.

Copyright: (c) 2021 by the authors. Licensee MDPI, Basel, Switzerland. This article is an open access article distributed under the terms and conditions of the Creative Commons Attribution (CC BY) license (https:// creativecommons.org/licenses/by/ $4.0 /)$.

Simple Summary: Aedes aegypti is the principal vector of major human pathogens, including dengue, Zika, chikungunya, and yellow fever viruses. Vector control relies mostly on the use of pyrethroid insecticides that kill mosquitoes by disabling the nervous system through binding to the voltage-gated sodium channel (vgsc). Resistance mechanisms have evolved most commonly as mutations in the vgsc gene or in genes associated with detoxification. These mutations are thought to associate with fitness costs, such that the frequency of resistant genotypes should decrease in the absence of insecticide use, and this assumption is critical to managing resistance through insecticide rotation strategies. While most studies to date have investigated life history parameters such as fecundity, we sought to investigate whether environmental stress resistance traits might also vary with insecticide resistance. We found, contrary to our expectations, that a strain selected for enhanced insecticide resistance had higher thermotolerance than its sister insecticide susceptible counterpart. Overall, our results indicate that abiotic resistance traits can correlate with insecticide resistance in surprising and variable ways, potentially complicating the management of insecticide resistance in the field.

Abstract: The study of fitness costs of insecticide resistance mutations in Aedes aegypti has generally been focused on life history parameters such as fecundity, mortality, and energy reserves. In this study we sought to investigate whether trade-offs might also exist between insecticide resistance and other abiotic stress resistance parameters. We evaluated the effects of the selection for permethrin resistance specifically on larval salinity and thermal tolerance. A population of A. aegypti originally from Southern Mexico was split into two strains, one selected for permethrin resistance and the other not. Larvae were reared at different salinities, and the fourth instar larvae were subjected to acute thermal stress; then, survival to both stresses was compared between strains. Contrary to our predictions, we found that insecticide resistance correlated with significantly enhanced larval thermotolerance. We found no clear difference in salinity tolerance between strains. This result suggests that insecticide resistance does not necessarily carry trade-offs in all traits affecting fitness and that successful insecticide resistance management strategies must account for genetic associations between insecticide resistance and abiotic stress resistance, as well as traditional life history parameters.

Keywords: climate; fitness; heat stress; insecticide resistance; mosquito; osmotic stress

\section{Introduction}

The evolution of insecticide resistance is a well-known phenomenon that has been observed in many species in response to all major classes of insecticides [1,2]. Resistance can evolve via multiple mechanisms, including improved metabolic detoxification, point mutations affecting the sensitivity of target proteins, and reduced penetration of the cuticle [3-6]. Such resistance mechanisms have a significant adaptive value for the organism under 
conditions of insecticide use; however, they induce physiological changes that can negatively impact fitness and lead to a reversion to the susceptible phenotype in the absence of insecticide selective pressure [7-9]. Adding complexity to this picture, the correlated fitness effects of resistance may change over time in a population as new mutations arise and interact with others [10]. Since insecticide resistance management (IRM) strategies such as insecticide rotation rely on resistance mutations having negative fitness costs, it is critical to gain a better understanding of how these mutations correlate with life history and environmental stress resistance traits in mosquitoes. Identifying the occurrence and mechanistic origins of such fitness correlates is not only important for modeling the effects of insecticide applications on population dynamics but might also provide new tools for vector control.

The reduced fitness of resistant genotypes has been documented for numerous species and insecticides [8]. Reduced fitness was found to take the form of reduced fecundity or reproductive rate [11-13], higher mortality [14], lower body mass [9], and even lower rates of courtship [15]. Such fitness effects of resistance may come as a result of direct or pleiotropic effects of the resistant genes themselves, of alleles at nearby loci co-segregating with the resistance allele, or of trade-offs in resource allocation $[9,16,17]$. Despite the assumption that resistance often comes with a fitness trade-off, research has shown that this is not always the case; in fact, some studies have found the opposite. For example, malathion-resistant Tribolium castaneum (Coleoptera: Tenebrionidae) showed enhanced male reproductive success and increased female fecundity [18,19]. Additionally, a lab population of Anopheles funestus (Diptera: Culicidae) selected for pyrethroid resistance was found to have a higher ratio of females, a higher proportion of females that successfully produced eggs, and a higher proportion of eggs surviving to adulthood when compared to its susceptible counterpart [20]. This paints a mixed picture across species and insecticides, leading researchers to question which mechanisms promote the maintenance of resistance alleles in populations [21,22].

Aedes aegypti (Diptera: Culicidae) is a container dwelling mosquito species that is closely associated with urban areas throughout the tropics and subtropics and is also the principal vector of dengue, Zika, chikungunya, Rift Valley fever, and yellow fever viruses. Heavy insecticide use has led to a rapid rise in resistance genotypes worldwidein particular, mutations in the voltage-gated sodium channel transmembrane gene (vgsc, aaeNav, LOC5567355) that are called kdr mutations (knockdown resistance) because they reduce pyrethroid binding $[23,24]$. Recent surveys from Southern Mexico have found that pyrethroid use has resulted in locally adapted and genetically differentiated populations [25], and that geographically distinct populations respond differently to the interruption of insecticide use with some losing resistance faster than others [26]. This provides evidence of a mosaic of dynamic resistance genotypes across the landscape, each with their unique, environment-dependent fitness costs. As in other species, studies on the fitness costs of insecticide resistance in A. aegypti have mostly focused on traditional life history parameters. Resistant populations have generally shown negative fitness effects, such as lower fecundity and hatchability [27-29], higher adult mortality rates [30-32], and even lower energy reserves [30]. No studies to date have examined the tolerance of $A$. aegypti to abiotic stresses found in the field. Yet, such factors, which vary in space and time, are likely to have major effects on the survival rates of alternate genotypes.

In the field, larvae and adults of $A$. aegypti are subjected to many abiotic stressors, such as thermal extremes and dehydration. Climate is the principal factor affecting the global distribution of $A$. aegypti. Studies have shown that complete larval development cannot occur at temperatures lower than $10-16^{\circ} \mathrm{C}$ and above $36^{\circ} \mathrm{C}[33,34]$. Immature stages are particularly sensitive to temperature due to the fact that they live in small, isolated pools and cannot easily escape unfavorable conditions [35]. Larvae may also be subject to shifting water chemistry as the water in their habitat evaporates [36]. Adults can be subject to dehydration stress, a factor known to impact the geographical distribution, reproductive capacity, and longevity of arthropods [37,38]. In sum, the physical environment exerts a 
strong selective pressure on mosquitoes. Therefore, the dynamics of insecticide resistance in field populations should be examined not only in the context of life-history trade-offs but, also, through the lens of abiotic stress resistance.

In the present study, we examine temperature and osmotic stress resistance in two strains originating from differential selection for insecticide resistance. The originating population, collected in the Yucatan Peninsula and insecticide-resistant, was reared in the lab for several generations without exposure to insecticide and then split into two strains, one selected for permethrin resistance and the other not. We took advantage of this selection regime to examine whether these sister strains originating from a common background differed significantly in several key abiotic stress resistance factors, as well as some life history traits. We hypothesized that selection for enhanced insecticide resistance should incur negative trade-offs in both abiotic stress resistance and life history traits. This is the first study to investigate the effects of selection for insecticide resistance on abiotic stress tolerance in A. aegypti and, in so doing, establishes straightforward protocols for such tests. Highlighting the possible links between abiotic stress resistance and insecticide resistance is of particular importance in the context of climate and land use changes, as possible interactive effects may help or hinder the spread of resistance genotypes to new locations [39].

\section{Materials and Methods}

Eggs of two A. aegypti strains created from a population originally collected in the Vergel neighborhood of Merida, Yucatan, Mexico were obtained from the lab of W.C. Black IV at Colorado State University (Fort Collins, CO, USA). As a result of field selection by permethrin used in vector control programs in the region, the original population carried at least two mutations in the voltage-gated sodium channel that are known to confer knockdown resistance: a valine-to-isoleucine replacement in codon 1016 (V1016I) and a phenylalanine-to-cysteine replacement in codon 1534 (F1534C). The population was reared in the lab without exposure to insecticide for 8 generations, resulting in a loss of insecticide resistance. The F8 population was then split into two strains, Vergelresistant (Vr) and Vergel-susceptible (Vs), with Vr exposed to 10-25 $\mu \mathrm{g}$ of permethrin every 3rd generation (to allow some recovery of fitness between bouts of selection) and Vs reared without selection. The eggs obtained for this experiment were from F29 (from the original date of field collection) for both strains. Bottle bioassay tests for permethrin LC50 on the F27, in which mosquitoes are placed in a glass bottle coated with insecticide for one hour and mortality is scored following a 24-h recovery time [26], found that $\mathrm{Vr}$ was 10-fold more resistant than Vs (Saavedra-Rodriguez, pers. com.). Random genetic drift should be minimal, as populations sizes were maintained at around 1000 individuals. We genotyped 108 female mosquitoes from the Vs strain and 108 from the Vr strain to assess the frequency of V1016I and F1534C mutations [40,41]. Briefly, we extracted DNA from individual mosquitoes following the methods described in [40] and performed two separate RT-PCRs (CFX96 Real-Time System, Bio-Rad, Hercules, CA, USA), each utilizing sets of primers corresponding to one or the other mutation. Expected haplotype frequencies of the combined V1016I and F1534C were calculated based upon the observed allele frequencies obtained from genotyping. For each of the 9 possible allelic combinations, the expected genotype frequencies were calculated considering the frequency of each allele from the haplotypes, so a mosquito that was VVFF (double homozygote-recessive) would have probability $(\mathrm{pV} \times \mathrm{pV} \times \mathrm{pF} \times \mathrm{pF})$. These expected frequencies were then compared to the observed haplotype frequencies in order to test for linkage disequilibrium using a chi-square test.

For thermotolerance experiments, eggs were hatched, and larvae reared in clear deionized water in an incubator set at $26^{\circ} \mathrm{C}$ and 12-h:12-h L:D (same conditions as they had been maintained in at Colorado State University). When larvae were 2 days old, they were split into replicate containers of 30 larvae / 350-mL water. The larvae were provided food daily (1:1 ground-up Tetramin ${ }^{\circledR}$ fish flakes and Baker's yeast). Thermotolerance of 
4th instar larvae was examined by subjecting individuals to thermal stress for various durations and assessing survival $24 \mathrm{~h}$ later. For each trial, thirty 4 th instar larvae from each strain were placed individually in $13 \mathrm{~mm} \times 100 \mathrm{~mm}$ glass culture tubes with approximately $2 \mathrm{~mL}$ water. The 60 tubes were then immersed in a water bath set at $42{ }^{\circ} \mathrm{C}$ (Thermo Electron Corporation, Walmath, MA, USA). Preliminary tests found that larvae died within minutes at $44{ }^{\circ} \mathrm{C}$ but survived multiple hours at $40{ }^{\circ} \mathrm{C}$. Therefore, $42{ }^{\circ} \mathrm{C}$ was chosen, as it promoted survival long enough to discriminate resistance to acute thermal stress while minimizing the possibility for additional variables (such as the production of heat shock proteins, for example) to affect the survival rates at the different time points. A thermocouple was placed in an extra culture tube to monitor the water temperature. Sets of 6 tubes per strain were removed from the water bath at 40,50, 55, 60, and $70 \mathrm{~min}$ and then immediately placed in a room temperature water bath for $10 \mathrm{~min}$ to return the water temperature to ambient. Larvae were then pooled into new containers according to strain and stress duration, provided food, and left to recover overnight. The next day, larvae capable of diving and returning to the surface were counted as alive while those unable to do so were counted as dead. We performed 17 trials for this experiment.

For salinity tolerance experiments, eggs were placed (approximately 200 eggs per $350 \mathrm{~mL}$ container) in deionized water with either $0,4,8$, or $12 \mathrm{~g}$ of aquarium salt per liter (corresponding to 0-37.5\% sea water; Instant Ocean, Blacksburg, VA, USA). The upper salinity was chosen, because it is known to affect the survival of $A$. aegypti larvae without causing significant mortality [36]. Each day, new hatchlings were transferred to a separate container of the same salinity, and the hatching date was noted for each container. In total, we made 8 replicate larval containers of 19-22 larvae for each salinity and each strain $(8 \times 4 \times 2=64$ containers in total). Mosquitoes were monitored throughout larval development and then transferred to emergence cages on the day of pupation. Upon emergence, adult females were $\mathrm{CO}_{2}$-anesthetized, and wet mass was determined using a microbalance (Toledo XP26, Mettler, Columbus, OH, USA). Each mosquito was then dried at $70{ }^{\circ} \mathrm{C}$ for $24 \mathrm{~h}$ and weighed again to determine dry mass. We were careful to include representatives from all replicate containers and diverse larval durations in our adult mass measurements. Results are expressed as dry mass in mg and dry mass-specific (dms) body water content (by dividing water by dry mass) in order to standardize values for the variations in body mass among the mosquitoes. A total of 40 females were measured per salinity and strain.

Chi-square tests for linkage disequilibrium were performed by hand, while all other statistical tests were performed using the statistical software package SPSS version 25.0 (IBM SPSS Statistics, Armonk, NY, USA). Data were first tested for normality. For those data that did not fit a normal distribution (\% larval survival relative to thermal stress and to salinity), Mann-Whitney $U$ tests were used to examine the effects of strain on the dependent variable. In other cases, univariate general linear models were used with strain and salinity as the fixed factors. Bars in the figures represent the standard error of the mean (S.E.M.). In cases where significant interaction effects were detected between strain and salinity, we made pairwise comparisons between strains at each salinity using either $t$-tests or Mann-Whitney $U$ tests, with a Bonferroni-corrected $\alpha$ of 0.0125 . Salinities where a significant difference was found between strains are indicated with an asterisk in the figures.

\section{Results}

\subsection{Strain Haplotypes}

We found that the 1016I allele frequency was 0.16 in Vs and 0.85 in $\mathrm{Vr}$, and the $1534 \mathrm{C}$ allele frequency was 0.17 in Vs and 0.85 in Vr. Both strains were found to be in HardyWeinberg equilibrium at both loci. Concerning the association between both loci, Vs was composed of $61 \%$ double-susceptible homozygotes (VVFF), while Vr was composed of $69 \%$ double-resistant homozygotes (IICC) (Figure 1). The next most common genotype, in both strains, was the double heterozygote (VIFC). The two loci were found to be in significant 
linkage disequilibrium in both strains (Table 1), with 1016V associated with 1534F and 1016I with 1534C.

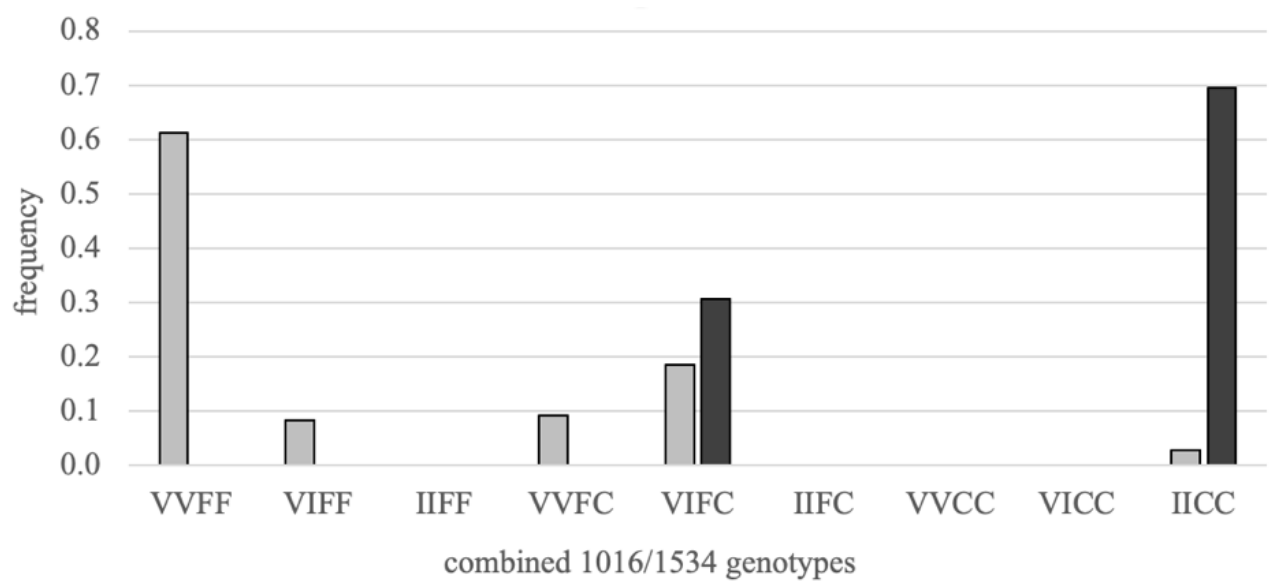

Figure 1. The frequency of 1016/1534 genotypes for both the susceptible and resistant strains used in the study. Randomly selected females from the susceptible (light bars) and resistant (dark bars) strains were genotyped for both V1016I and F1534C knockdown resistance (kdr) mutations. Double homozygote-susceptible individuals (VVFF) are on the far left and double homozygote-resistant (IICC) on the far right.

Table 1. Observed and expected haplotype numbers in both strains, with the standardized disequilibrium value and test of significance of the linkage disequilibrium. Vs: Vergel-susceptible, Vr: Vergel-resistant. For haplotypes, the first letter represents the allele at the 1016 locus and the second letter represents the allele at the 1534 locus.

\begin{tabular}{|c|c|c|c|c|c|c|c|}
\hline Strain & Haplotypes & Observed N & Expected N & $\mathrm{D}^{\prime}$ & SumSquares & Chi-Square & $p$-Value \\
\hline \multirow[t]{4}{*}{ Vs } & VF & 322 & 302 & 0.35 & 1.37 & 50.75 & $<0.001$ \\
\hline & $\mathrm{VC}$ & 40 & 60 & & 6.85 & & \\
\hline & IF & 38 & 58 & & 7.09 & & \\
\hline & IC & 32 & 12 & & 35.44 & & \\
\hline \multirow[t]{4}{*}{$\mathrm{Vr}$} & VF & 33 & 10 & 0.41 & 52.08 & 72.56 & $<0.001$ \\
\hline & $\mathrm{VC}$ & 33 & 56 & & 9.39 & & \\
\hline & IF & 33 & 56 & & 9.39 & & \\
\hline & IC & 333 & 310 & & 1.69 & & \\
\hline
\end{tabular}

\subsection{Larval Thermotolerance}

Overall, Vr larvae showed significantly higher survival than Vs larvae when exposed to a thermal stress of $42{ }^{\circ} \mathrm{C}$, with median values of 68.7 and 37.5 , respectively (total $N=170$, $\mathrm{U}=2101, \mathrm{Z}=-4.776, p<0.001$; Figure 2). Assuming a linear change in survival over the timeframe of measurement, 50\% mortality occurred at approximately $50 \mathrm{~min}$ for Vs and $64 \mathrm{~min}$ for $\mathrm{Vr}$.

\subsection{Larval Survival and Duration at Different Salinities}

We found no overall significant difference in larval survival between both strains within the range of salinities tested, with median values of $95 \%$ for $\mathrm{Vr}$ and $100 \%$ for $\mathrm{Vs}$ (total $N=64, \mathrm{U}=551.5, \mathrm{Z}=0.570, p=0.569$; Figure 3a). The larval duration was not affected by the strain (degree of freedom (df) $=1, \mathrm{~F}=0.159, p=0.692$ ); however, it was affected by the salinity $(\mathrm{df}=3, \mathrm{~F}=24.487, p<0.001)$, and the effect was strain-dependent $(\mathrm{df}=3$, $\mathrm{F}=4.437, p=0.007$; Figure 3b). Specifically, the larval development of Vs was delayed in both freshwater and $12 \mathrm{~g} \cdot \mathrm{L}^{-1}$, whereas the larval development of $\mathrm{Vr}$ was delayed only at the highest salinity. The delay in development at $12 \mathrm{~g} \cdot \mathrm{L}^{-1}$ was significantly stronger in $\mathrm{Vr}$ than in $\mathrm{Vs}(p=0.010)$. 


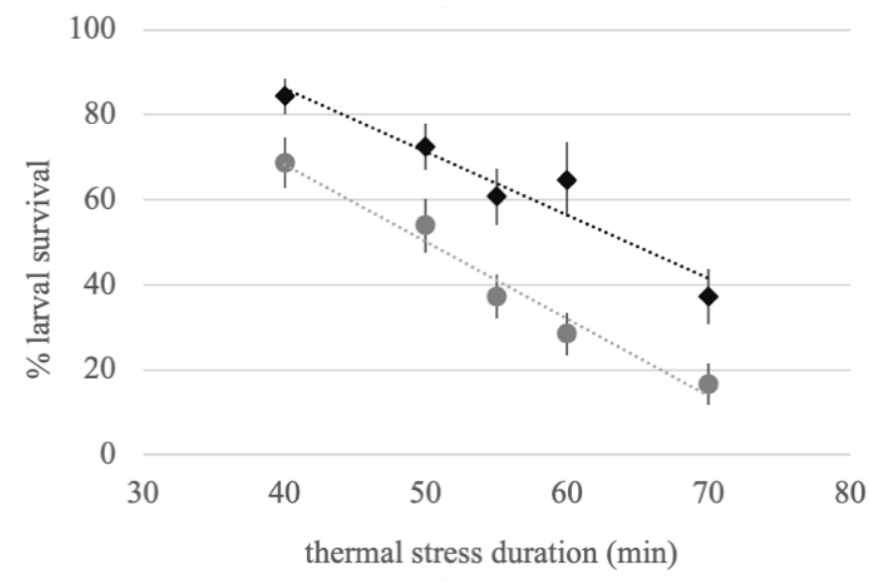

Figure 2. Effect of thermal stress on the larval survival of insecticide-resistant and -susceptible Aedes aegypti strains. Percentage of larvae still alive $24 \mathrm{~h}$ post-treatment following a $42{ }^{\circ} \mathrm{C}$ thermal stress of variable duration. The grey circles represent Vergel-susceptible (Vs), and the black diamonds represent Vergel-resistant (Vr). Bars represent S.E.M.

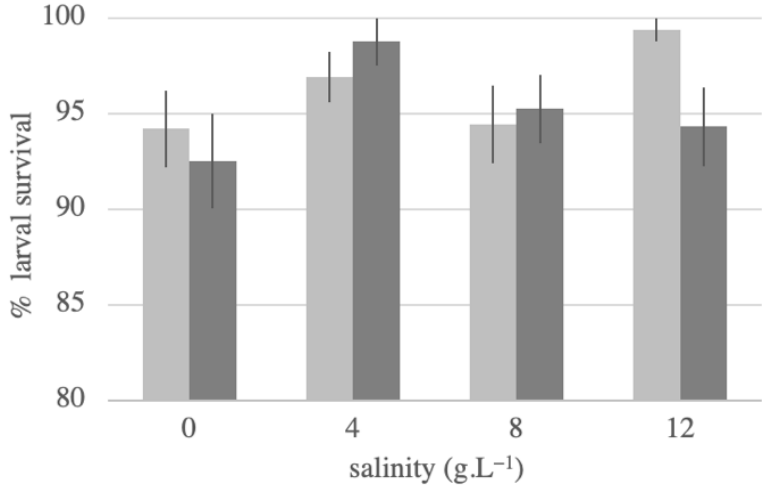

(a)

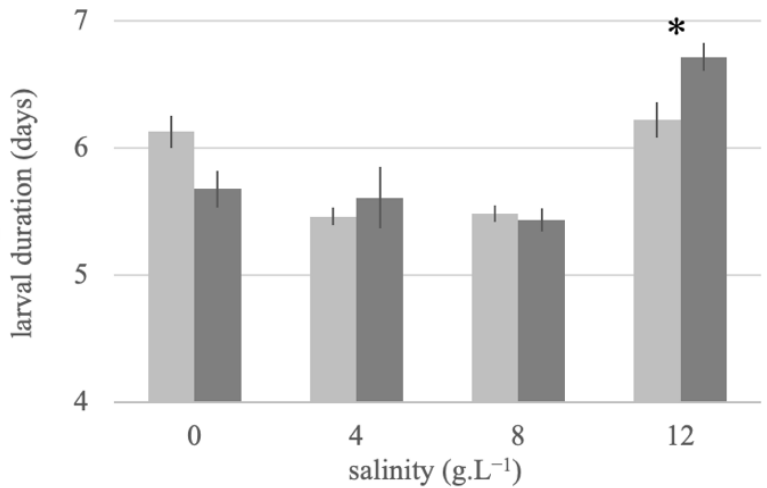

(b)

Figure 3. Effect of water salinity on the larval development success and duration. (a) Average percent of larvae that successfully pupated in each container. (b) Average number of days until pupation for larvae in each container. Light grey columns represent insecticide-susceptible larvae Vs, and dark grey columns represent insecticide-resistant larvae Vr. Bars represent S.E.M. Significant differences between strains within each salinity group are represented by an asterisk.

\subsection{Adult Dry Mass and Water Stores of Females Reared at Different Salinities}

Newly emerged females of both strains did not differ significantly in their overall dry mass $(\mathrm{df}=1, \mathrm{~F}=0.393, p=0.531$; Figure $4 \mathrm{a})$. However, the dry mass was affected by salinity $(\mathrm{df}=3, \mathrm{~F}=22.272, p<0.001)$, and the effect was strain-specific $(\mathrm{df}=3, \mathrm{~F}=14.901, p<0.001)$. In particular, $\mathrm{Vr}$ had a significantly higher mass than Vs at extreme salinities, but Vs had a significantly higher mass than $\mathrm{Vr}$ at $4 \mathrm{~g} \cdot \mathrm{L}^{-1}$. Water reserves were significantly affected by both strain $(\mathrm{df}=1, \mathrm{~F}=22.069, p<0.001$; Figure $4 \mathrm{~b})$ and by salinity $(\mathrm{df}=3, \mathrm{~F}=7.911$, $p<0.001)$, with the effect of salinity being strain-specific ( $\mathrm{df}=3, \mathrm{~F}=5.084, p=0.002)$. While the $\mathrm{Vr}$ water content was relatively unaffected by larval salinity, the susceptible strain showed a significantly higher body water content compared to $\mathrm{Vr}$ if larvae were reared either in freshwater or $12 \mathrm{~g} \cdot \mathrm{L}^{-1}$. 


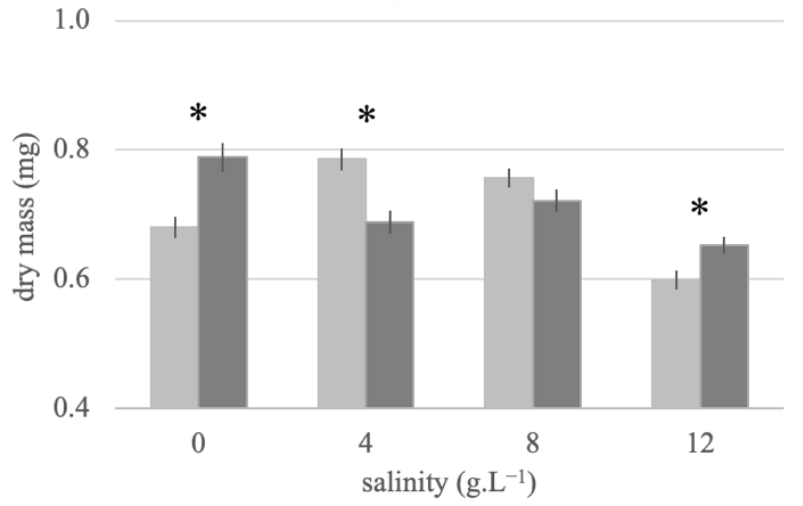

(a)

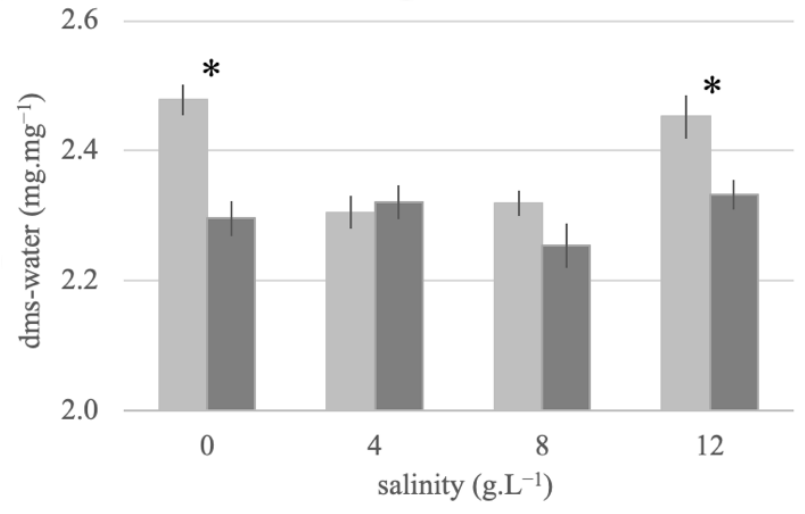

(b)

Figure 4. Body characteristics of newly emerged female mosquitoes from insecticide-susceptible (Vs) and -resistant (Vr) A. aegypti strains reared at different salinities. (a) Dry mass and (b) dry mass-specific water content. Light grey columns represent Vs adult females, and dark grey columns represent Vr adult females. Bars represent S.E.M. Significant differences between the strains within each salinity group are represented by an asterisk.

\section{Discussion}

In the present study, we examined two mosquito strains originating from one location in Southern Mexico, then differentially selected for insecticide resistance. We measured the frequency of alleles at two loci known to associate with insecticide resistance and found them to differ significantly among the strains. Furthermore, we found the alleles at both loci to be in linkage disequilibrium. The vast majority of mosquitoes tested were either double homozygote-susceptible (for the Vs strain) or double homozygote-resistant (for Vr), and the next most common combination was double heterozygotes for both strains. Mutations at sites 1534 and 1016 of the VGSC cooccur widely throughout the Americas [42-45]. Hypotheses for the association include one compensating for the negative fitness effects of the other [24] or enhancing the insensitivity caused by the other [23]. The distribution pattern we found provides support for the concept of synergism between both. The strains studied here likely carry other resistance mutations that were not genotyped but may also influence the observed differences between strains.

The experiment presented here allowed us to compare fitness traits in two strains with identical genetic backgrounds but differentially selected for permethrin resistance over multiple generations. Contrary to our expectations, we found a significant positive effect of insecticide resistance selection on larval thermotolerance. A. aegypti is a container-dwelling species where larvae are restricted to small, shallow bodies of water such as abandoned tires [46], in which abiotic factors may vary widely for the duration of their development. Furthermore, the high specific heat and thermal conductivity of water ensure that the body temperature of the larva closely matches that of the surrounding water. Our findings indicate that insecticide resistance may correlate with enhanced larval survival under heat-stressed field conditions for $A$. aegypti. The mechanisms limiting insect survival at the upper thermal extremes are not fully understood but may involve multiple factors. For example, protein denaturation [47] may lead to a breakdown of neuromuscular or metabolic processes. Amino acid substitutions resulting from mutations either in genes directly involved in insecticide resistance or in those co-segregating with resistance genes may affect protein stability at high temperature [48]. It has also been hypothesized that, at very high temperature, oxygen delivery may become insufficient to meet metabolic demand [49]. Aquatic organisms that obtain oxygen directly from the water are indeed prone to oxygen deprivation at high ambient temperatures [50,51]. Mosquito larvae, however, obtain oxygen from the air via their siphon, so this factor is unlikely to dictate thermotolerance $[52,53]$. Other possible differences between strains include the management of reactive oxygen species produced during thermal stress [54,55], the homeoviscous adapta- 
tion potential of the cell membrane [56,57], or differential heat shock protein expression among the strains [58-61]. Heat Shock Protein STI1, for example, a protein that may act as a cochaperone mediating the activity of HSP70 and HSP90 [62,63], was found to genetically associate with insecticide resistance in A. aegypti [64]. Further studies will be necessary to help determine which physiological mechanisms set the upper thermal limits in mosquito larvae and how these are affected by selection for insecticide resistance.

To our knowledge, this was the first study to examine the impact of insecticide resistance selection on larval salinity tolerance in A. aegypti. While larval survival was not affected by selection for enhanced insecticide resistance, our study found a difference between strains in larval duration at extreme salinities. Specifically, compared to the susceptible strain, the resistant strain took longer to pupate at the highest salinity but less time at the lowest salinity. A. aegypti are freshwater osmoconformers who lack a salt-secreting rectal gland and are thus limited to environments more dilute than their hemolymph osmotic pressure [65]. Larval survival of $A$. aegypti is possible in fresh and brackish water [66] but drops rapidly beyond $10-15 \mathrm{~g} \cdot \mathrm{L}^{-1}$ [36,67]. Larval duration was shortest at $7 \mathrm{~g} \cdot \mathrm{L}^{-1}$, suggesting that the osmoregulatory cost may be lowest at a moderate salinity, allowing more energy to be dedicated to growth [36]. A short larval duration is a relevant fitness trait, as larvae may be at high risk of predation and evaporation of their habitat prior to pupation. The difference in larval duration between strains that we observed at extreme salinities may reflect an altered osmoregulatory ability, wherein the resistant strain shows a lower cost of osmoregulation in hypoosmotic conditions but a higher cost and lower fitness in the hyperosmotic medium. This result suggests that salinity tolerance may also be worth examining in the context of traits affecting the fitness of insecticide resistance genotypes.

As expected, we found that larvae grown at higher salinities produced adults of lower mass. Salinity was previously found to affect the growth rate and larval duration in a nonproportional manner, such that adult mass is negatively affected by a high larval salinity [36]. While no significant difference in dry mass was found between the strains overall, mass varied between strains within the salinity groups. In particular, the resistant strain had a higher dry mass in freshwater than the susceptible strain, despite showing a shorter larval duration. The combined rapid growth rate and large adult mass may represent again a selective advantage for the resistant strain in a typically inhospitable larval habitat. An increased body size has generally been thought of as a fitness advantage due to the fact that larger females can ingest more blood and produce more eggs [35]. However, a larger mass may also indicate a thicker cuticle, a feature that has direct benefits in conferring penetration resistance to insecticides $[6,68,69]$ but may otherwise carry an increased cost during flight [70]. Future studies should include measurements of wing size in addition to body mass, as this metric would allow researchers to tease apart the relative contributions of body dimension and cuticular mass to the overall body mass.

The difference in mass-corrected body water content between strains at $0 \mathrm{~g} \cdot \mathrm{L}^{-1} \mathrm{might}$ reflect a difference in relative cuticle mass. Indeed, if mosquitoes of both strains have similar tissue hydration, the resistant females may appear to have less water simply because a larger portion of their mass is composed of relatively dry cuticle. However, body water differences can also be explained by variation in energy storage strategies. The susceptible female may be storing most of her energy as glycogen, which has been shown to bind up to three times its weight in water [71]. Teasing apart the mechanistic reasons for the differences observed, and their potential fitness implications, will require measuring glycogen stores, as well as cuticular thickness, via transmission electron microscopy and/or expression patterns of cuticle-related cytochrome P450s and cuticular proteins involved in cuticle thickening. These investigations would also provide valuable information on the possible additional mechanisms of insecticide resistance in A. aegypti. 


\section{Conclusions}

Selection for enhanced insecticide resistance in this population led to a series of unexpected changes, including at least one fitness benefit, increased larval thermotolerance, highlighting the association between insecticide resistance and abiotic stress resistance traits. Under field conditions, enhanced larval thermotolerance could result in a rapid selective sweep following a particular climate event driving the insecticide resistance of local populations closer to fixation. Larval habitat salinity may also selectively influence the fitness of alternate populations by affecting factors such as body size, energy storage, or cuticular thickness in the adults. Associations between insecticide resistance and other fitness traits may result from genetic linkages, possibly within chromosomal inversions [72] or micro-inversions [73], such as have already been observed in Drosophila melanogaster [74] and Anopheles spp. [75]. Understanding which fitness-related genes associate with insecticide resistance genes will not only provide crucial information on how weather and climate affect the insecticide resistance of field populations but, more importantly, the integration of that knowledge into management strategies could lead to more effective control of vector populations and ultimately reduce the spread of disease.

Author Contributions: Conceptualization, K.A., K.S.-R., W.C.B.IV, and E.M.G.; formal analysis, E.M.G.; funding acquisition, K.A. and E.M.G.; investigation, K.A. and E.M.G.; methodology, K.A. and E.M.G.; resources, K.S.-R., W.C.B.IV, and E.M.G.; supervision, E.M.G.; validation, E.M.G.; visualization, K.A. and E.M.G.; writing—original draft, K.A. and E.M.G.; and writing—review and editing, K.A., K.S.-R., W.C.B.IV, and E.M.G. All authors have read and agreed to the published version of the manuscript.

Funding: This research was funded through a Colorado College Faculty-Student collaborative grant to E.M.G. and K.A.

Institutional Review Board Statement: Not applicable.

Data Availability Statement: Data available upon request.

Acknowledgments: We would like to thank Sara Hanson, Olivia Frey, Becki Sandvos, Maddie Sorensen, Maddy Webster, Kristen Kinchla, Kate McGinn and Erika Kaszczyszyn for their intellectual and technical support. We would also like to thank the 3 anonymous reviewers for their invaluable suggestions on a previous draft.

Conflicts of Interest: The authors declare no conflict of interest.

\section{References}

1. Davies, T.G.E.; Field, L.M.; Usherwood, P.N.R.; Williamson, M.S. DDT, pyrethrins, pyrethroids and insect sodium channels. TBMB 2007, 59, 151-162. [CrossRef] [PubMed]

2. Hemingway, J. Resistance: A problem without an easy solution. Pestic. Biochem. Physiol. 2018, 151, 73-75. [CrossRef] [PubMed]

3. Hemingway, J.; Hawkes, N.J.; McCarroll, L.; Ranson, H. The molecular basis of insecticide resistance in mosquitoes. Insect Biochem. Mol. Biol. 2004, 34, 653-665. [CrossRef] [PubMed]

4. Liu, N. Insecticide Resistance in Mosquitoes: Impact, Mechanisms, and Research Directions. Annu. Rev. Entomol. 2015, 60, 537-559. [CrossRef]

5. Balabanidou, V.; Kampouraki, A.; MacLean, M.; Blomquist, G.J.; Tittiger, C.; Juárez, M.P.; Mijailovsky, S.J.; Chalepakis, G.; Anthousi, A.; Lynd, A.; et al. Cytochrome P450 Associated with Insecticide Resistance Catalyzes Cuticular Hydrocarbon Production in Anopheles Gambiae. Proc. Natl. Acad. Sci. USA 2016, 113, 9268-9273. [CrossRef]

6. Balabanidou, V.; Grigoraki, L.; Vontas, J. Insect cuticle: A critical determinant of insecticide resistance. Curr. Opin. Insect Sci. 2018, 27, 68-74. [CrossRef]

7. Rivero, A.; Magaud, A.; Nicot, A.; Vézilier, J. Energetic Cost of Insecticide Resistance in Culex pipiens Mosquitoes. J. Med. Entomol. 2011, 48, 694-700. [CrossRef]

8. Kliot, A.; Ghanim, M. Fitness costs associated with insecticide resistance. Pest Manag. Sci. 2012, 68, 1431-1437. [CrossRef]

9. Carrière, Y.; Deland, J.P.; Roff, D.A.; Vincent, C. Life-history costs associated with the evolution of insecticide resistance. Proc. $R$. Soc. Lond. B 1994, 258, 35-40. [CrossRef]

10. Labbé, P.; Berticat, C.; Berthomieu, A.; Unal, S.; Bernard, C.; Weill, M.; Lenormand, T. Forty Years of Erratic Insecticide Resistance Evolution in the Mosquito Culex pipiens. PLoS Genet. 2007, 3, e205. [CrossRef]

11. Sayyed, A.H.; Ahmad, M.; Crickmore, N. Fitness Costs Limit the Development of Resistance to Indoxacarb and Deltamethrin in Heliothis virescens (Lepidoptera: Noctuidae). J. Econ. Entomol. 2008, 101, 1927-1933. [CrossRef] [PubMed] 
12. Gordon, J.R.; Michael, F.P.; Haynes, K.F. Insecticide resistance in the bed bug comes with a cost. Sci. Rep. 2015, 5, 10807. [CrossRef] [PubMed]

13. Liu, Z.; Han, Z. Fitness costs of laboratory-selected imidacloprid resistance in the brown planthopper, Nilaparvata lugens Stål. Pest. Manag. Sci. 2006, 62, 279-282. [CrossRef] [PubMed]

14. Fragoso, D.B.; Guedes, R.N.C.; Peternelli, L.A. Developmental rates and population growth of insecticide-resistant and susceptible populations of Sitophilus zeamais. J. Stored Prod. Res. 2005, 41, 271-281. [CrossRef]

15. Rostant, W.G.; Bowyer, J.; Coupland, J.; Facey, J.; Hosken, D.J.; Wedell, N. Pleiotropic Effects of DDT Resistance on Male Size and Behaviour. Behav. Genet. 2017, 47, 449-458. [CrossRef] [PubMed]

16. Maynard Smith, J.; Haigh, J. The hitch-hiking effect of a favourable gene. Genet. Res. 1974, 23, 23-35. [CrossRef]

17. Ardia, D.R.; Gantz, J.E.; Brent, C.; Schneider; Strebel, S. Costs of immunity in insects: An induced immune response increases metabolic rate and decreases antimicrobial activity: Energetic costs of immunity. Functional. Ecol. 2012, 26, 732-739. [CrossRef]

18. Arnaud, L.; Haubruge, E. Insecticide resistance enhances male reproductive success in a beetle. Evolution 2002, 56, 2435-2444. [CrossRef]

19. Arnaud, L.; Brostaux, Y.; Assie, L.; Gaspar, C.; Haubruge, E. Increased fecundity of malathion-specific resistant beetles in absence of insecticide pressure. Heredity 2002, 89, 425-429. [CrossRef]

20. Okoye, P.N.; Brooke, B.D.; Hunt, R.H.; Coetzee, M. Relative developmental and reproductive fitness associated with pyrethroid resistance in the major southern African malaria vector, Anopheles funestus. Bull. Entomol. Res. 2007, 97, 599-605. [CrossRef]

21. ffrench-Constant, R.H.; Bass, C. Does resistance really carry a fitness cost? Curr. Opin. Insect Sci. 2017, 21, 39-46. [CrossRef] [PubMed]

22. Dusfour, I.; Vontas, J.; David, J.-P.; Weetman, D.; Fonseca, D.M.; Corbel, V.; Raghavendra, K.; Coulibaly, M.B.; Martins, A.J.; Kasai, S.; et al. Management of insecticide resistance in the major Aedes vectors of arboviruses: Advances and challenges. PLoS Negl. Trop. Dis. 2019, 13, e0007615. [CrossRef] [PubMed]

23. Du, Y.; Nomura, Y.; Zhorov, B.S.; Dong, K. Sodium channel mutations and pyrethroid resistance in Aedes aegypti. Insects 2016, 7, 60. [CrossRef] [PubMed]

24. Vera-Maloof, F.Z.; Saavedra-Rodriguez, K.; Elizondo-Quiroga, A.E.; Lozano-Fuentes, S.; Black, W.C., IV. Coevolution of the Ile1,016 and Cys1,534 Mutations in the Voltage Gated Sodium Channel Gene of Aedes aegypti in Mexico. PLoS Negl. Trop. Dis. 2015, 9, e0004263. [CrossRef]

25. Saavedra-Rodriguez, K.; Beaty, M.; Lozano-Fuentes, S.; Denham, S.; Garcia-Rejon, J.; Reyes-Solis, G.; Machain-Williams, C.; Loroño-Pino, M.A.; Flores-Suarez, A.; Ponce-Garcia, G.; et al. Local evolution of pyrethroid resistance offsets gene flow among Aedes aegypti collections in Yucatan State, Mexico. Am. J. Trop. Med. Hyg. 2015, 92, 201-209. [CrossRef]

26. Vera-Maloof, F.Z.; Saavedra-Rodriguez, K.; Penilla-Navarro, R.P.; Rodriguez-Ramirez, D.A.; Dzul, F.; Manrique-Saide, P.; Black, W.C. Loss of pyrethroid resistance in newly established laboratory colonies of Aedes aegypti. PLoS Negl. Trop. Dis. 2020, 14, e0007753. [CrossRef]

27. Brito, L.P.; Linss, J.G.B.; Lima-Camara, T.N.; Belinato, T.A.; Peixoto, A.A.; Lima, J.B.P.; Valle, D.; Martins, A.J. Assessing the Effects of Aedes aegypti kdr Mutations on Pyrethroid Resistance and Its Fitness Cost. PLoS ONE 2013, 8, e60878. [CrossRef]

28. Kumar, S.; Thomas, A.; Samuel, T.; Sahgal, A.; Verma, A.; Pillai, M.K.K. Diminished reproductive fitness associated with the deltamethrin resistance in an Indian strain of dengue vector mosquito, Aedes aegypti L. Tropical. Biomed. 2009, 26, 155-164.

29. Martins, A.J.; Ribeiro, C.D.e.M.; Bellinato, D.F.; Peixoto, A.A.; Valle, D.; Lima, J.B.P. Effect of insecticide resistance on development, longevity and reproduction of field or laboratory selected Aedes aegypti populations. PLoS ONE 2012, 7, e31889. [CrossRef]

30. Diniz, D.F.A.; de Melo-Santos, M.A.V.; de Santos, E.M.M.; Beserra, E.B.; Helvecio, E.; de Carvalho-Leandro, D.; dos Santos, B.S.; de Menezes Lima, V.L.; Ayres, C.F.J. Fitness cost in field and laboratory Aedes aegypti populations associated with resistance to the insecticide temephos. Parasites Vectors 2015, 8, 662. [CrossRef]

31. Garcia-Rejon, J.E.; Chan-Orilla, J.A.; Cigarroa-Toledo, N.; Chi-Chim, W.A.; Torres-Chable, O.M.; Cruz, G.A.; Machain-Williams, C.; Mendez-Galvan, J.; Tzuc, J.C.; Baak-Baak, C.M. Laboratory evaluation of the Ile1, 016 mutation-effect on several life-history parameters of Aedes aegypti. Int. J. Malar. Res. 2018, 5, 112-120.

32. Saingamsook, J.; Yanola, J.; Lumjuan, N.; Walton, C.; Somboon, P. Investigation of Relative Development and Reproductivity Fitness Cost in Three Insecticide-Resistant Strains of Aedes aegypti from Thailand. Insects 2019, 10, 265. [CrossRef] [PubMed]

33. Reinhold, J.; Lazzari, C.; Lahondère, C. Effects of the Environmental Temperature on Aedes aegypti and Aedes albopictus Mosquitoes: A Review. Insects 2018, 9, 158. [CrossRef] [PubMed]

34. Christophers, S.R. Aëdes aegypti (L.) the Yellow Fever Mosquito: Its Life History, Bionomics and Structure; Cambridge University Press: Cambridge, UK, 2009; ISBN 978-0-521-11302-1.

35. Clements, A.N. Development, Nutrition and Reproduction. In The Biology of Mosquitoes; CABI Publ.: Wallingford, UK, 2008; ISBN 978-0-85199-374-4.

36. Clark, T.M.; Flis, B.J.; Remold, S.K. Differences in the effects of salinity on larval growth and developmental programs of a freshwater and a euryhaline mosquito species (Insecta: Diptera, Culicidae). J. Exp. Biol. 2004, 207, 2289-2295. [CrossRef]

37. Addo-Bediako, A.; Chown, S.L.; Gaston, K.J. Revisiting water loss in insects: A large scale view. J. Insect Physiol. 2001, 47, 1377-1388. [CrossRef] 
38. Schmidt, C.A.; Comeau, G.; Monaghan, A.J.; Williamson, D.J.; Ernst, K.C. Effects of desiccation stress on adult female longevity in Aedes aegypti and Ae. albopictus (Diptera: Culicidae): Results of a systematic review and pooled survival analysis. Parasites Vectors 2018, 11, 267. [CrossRef]

39. Kraemer, M.U.G.; Reiner, R.C.; Brady, O.J.; Messina, J.P.; Gilbert, M.; Pigott, D.M.; Yi, D.; Johnson, K.; Earl, L.; Marczak, L.B.; et al. Past and future spread of the arbovirus vectors Aedes aegypti and Aedes albopictus. Nat. Microbiol. 2019, 4, 854-863. [CrossRef]

40. Saavedra-Rodriguez, K.; Urdaneta-Marquez, L.; Rajatileka, S.; Moulton, M.; Flores, A.E.; Fernandez-Salas, I.; Bisset, J.; Rodriguez, M.; McCall, P.J.; Donnelly, M.J.; et al. A mutation in the voltage-gated sodium channel gene associated with pyrethroid resistance in Latin American Aedes aegypti. Insect Mol. Biol. 2007, 16, 785-798. [CrossRef]

41. Yanola, J.; Somboon, P.; Walton, C.; Nachaiwieng, W.; Somwang, P.; Prapanthadara, L. High-throughput assays for detection of the F1534C mutation in the voltage-gated sodium channel gene in permethrin-resistant Aedes aegypti and the distribution of this mutation throughout Thailand. Tropical. Med. Int. Health 2011, 16, 501-509. [CrossRef]

42. Alvarez-Gonzalez, L.C.; Briceño, A.; Ponce-Garcia, G.; Villanueva-Segura, O.K.; Davila-Barboza, J.A.; Lopez-Monroy, B.; GutierrezRodriguez, S.M.; Contreras-Perera, Y.; Rodriguez-Sanchez, I.P.; Flores, A.E. Assessing the effect of selection with deltamethrin on biological parameters and detoxifying enzymes in Aedes aegypti (L.): Deltamethrin selection in Aedes aegypti. Pest. Manag. Sci. 2017, 73, 2287-2293. [CrossRef]

43. Ponce-García, G.; Del Río-Galvan, S.; Barrera, R.; Saavedra-Rodriguez, K.; Villanueva-Segura, K.; Felix, G.; Amador, M.; Flores, A.E. Knockdown Resistance Mutations in Aedes aegypti (Diptera: Culicidae) From Puerto Rico. J. Med. Entomol. 2016, 53, 1410-1414. [CrossRef] [PubMed]

44. Estep, A.S.; Sanscrainte, N.D.; Waits, C.M.; Bernard, S.J.; Lloyd, A.M.; Lucas, K.J.; Buckner, E.A.; Vaidyanathan, R.; Morreale, R.; Conti, L.A.; et al. Quantification of permethrin resistance and kdr alleles in Florida strains of Aedes aegypti (L.) and Aedes albopictus (Skuse). PLoS Negl. Trop. Dis. 2018, 12, e0006544. [CrossRef] [PubMed]

45. Linss, J.G.; Brito, L.; Garcia, G.; Araki, A.; Bruno, R.; Lima, J.B.; Valle, D.; Martins, A. Distribution and dissemination of the Val1016Ile and Phe1534Cys Kdr mutations in Aedes aegypti Brazilian natural populations. Parasit Vectors 2014, 7, 25. [CrossRef] [PubMed]

46. Lloyd, L.S.; Winch, P.; Ortega-Canto, J.; Kendall, C. Results of a Community-Based Aedes aegypti Control Program in Merida, Yucatan, Mexico. Am. J. Trop. Med. Hyg. 1992, 46, 635-642. [CrossRef] [PubMed]

47. Hochachka, P.W.; Somero, G.N. Biochemical Adaptation; Princeton University Press: Princeton, NJ, USA, 2016; ISBN 978-0-69164055-6.

48. Fields, P.A.; Dong, Y.; Meng, X.; Somero, G.N. Adaptations of protein structure and function to temperature: There is more than one way to "skin a cat. " J. Exp. Biol. 2015, 218, 1801-1811. [CrossRef] [PubMed]

49. Pörtner, H.O. Climate change and temperature-dependent biogeography: Oxygen limitation of thermal tolerance in animals. Naturwissenschaften 2001, 88, 137-146. [CrossRef] [PubMed]

50. Pörtner, H.O. Climate variations and the physiological basis of temperature dependent biogeography: Systemic to molecular hierarchy of thermal tolerance in animals. Comp. Biochem. Physiol. Part A Mol. Integr. Physiol. 2002, 132, 739-761. [CrossRef]

51. Chown, S.L.; Duffy, G.A.; Sørensen, J.G. Upper thermal tolerance in aquatic insects. Curr. Opin. Insect Sci. 2015, 11, 78-83. [CrossRef]

52. Klok, C.J.; Kaiser, A.; Lighton, J.R.B.; Harrison, J.F. Critical oxygen partial pressures and maximal tracheal conductances for Drosophila melanogaster reared for multiple generations in hypoxia or hyperoxia. J. Insect Physiol. 2010, 56, 461-469. [CrossRef]

53. McCue, M.D.; De Los Santos, R. Upper Thermal Limits of Insects Are Not the Result of Insufficient Oxygen Delivery. Physiol. Biochem. Zool. 2013, 86, 257-265. [CrossRef]

54. Lalouette, L.; Williams, C.M.; Hervant, F.; Sinclair, B.J.; Renault, D. Metabolic rate and oxidative stress in insects exposed to low temperature thermal fluctuations. Comp. Biochem. Physiol. Part A Mol. Integr. Physiol. 2011, 158, 229-234. [CrossRef] [PubMed]

55. Zhu, G.; Xue, M.; Luo, Y.; Ji, G.; Liu, F.; Zhao, H.; Sun, X. Effects of short-term heat shock and physiological responses to heat stress in two Bradysia adults, Bradysia odoriphaga and Bradysia difformis. Sci. Rep. 2017, 7, 13381. [CrossRef] [PubMed]

56. Hazel, J.; Williams, E. The role of alterations in membrane lipid composition in enabling physiological adaptation of organisms to their physical environment. Prog. Lipid Res. 1990, 29, 167-227. [CrossRef]

57. Martin-Creuzburg, D.; Coggins, B.L.; Ebert, D.; Yampolsky, L.Y. Rearing Temperature and Fatty Acid Supplementation Jointly Affect Lipid Fluorescence Polarization and Heat Tolerance in Daphnia. Physiol. Biochem. Zool. 2019, 92, 408-418. [CrossRef] [PubMed]

58. Feder, M.E.; Hofmann, G.E. Heat-shock proteins, molecular chaperones, and the stress response: Evolutionary and Ecological Physiology. Annu. Rev. Physiol. 1999, 61, 243-282. [CrossRef]

59. Gross, T.L.; Myles, K.M.; Adelman, Z.N. Identification and Characterization of Heat Shock 70 Genes in Aedes aegypti (Diptera: Culicidae). J. Med. Entomol. 2009, 46, 496-504. [CrossRef]

60. Sivan, A.; Shriram, A.N.; Muruganandam, N.; Thamizhmani, R. Expression of heat shock proteins (HSPs) in Aedes aegypti (L) and Aedes albopictus (Skuse) (Diptera: Culicidae) larvae in response to thermal stress. Acta Tropica 2017, 167, 121-127. [CrossRef]

61. Zhao, L.; Becnel, J.J.; Clark, G.G.; Linthicum, K.J. Expression of AeaHsp26 and AeaHsp83 in Aedes aegypti (Diptera: Culicidae) Larvae and Pupae in Response to Heat Shock Stress. Me 2010, 47, 367-375. [CrossRef]

62. Nicolet, C.M.; Craig, E.A. Isolation and Characterization of STIJ, a Stress-Inducible Gene from Saccharomyces cerevisiae. Mol. Cell. Biol. 1989, 9, 9. [CrossRef] 
63. Odunuga, O.O.; Longshaw, V.M.; Blatch, G.L. Hop: More than an Hsp70/Hsp90 adaptor protein. Bioessays 2004, 26, 1058-1068. [CrossRef]

64. Campbell, C.L.; Saavedra-Rodriguez, K.; Kubik, T.D.; Lenhart, A.; Lozano-Fuentes, S.; Black, W.C. Vgsc-interacting proteins are genetically associated with pyrethroid resistance in Aedes aegypti. PLoS ONE 2019, 14, e0211497. [CrossRef] [PubMed]

65. Bradley, T.J. Physiology of Osmoregulation in Mosquitoes. Annu. Rev. Entomol. 1987, 32, 439-462. [CrossRef] [PubMed]

66. Ramasamy, R.; Surendran, S.N.; Jude, P.J.; Dharshini, S.; Vinobaba, M. Larval Development of Aedes aegypti and Aedes albopictus in Peri-Urban Brackish Water and Its Implications for Transmission of Arboviral Diseases. PLoS Negl. Trop. Dis. 2011, 5, e1369. [CrossRef] [PubMed]

67. Wigglesworth, V.B. The Regulation of Osmotic Pressure and Chloride Concentration in the Haemolymph of Mosquito Larvae. J. Exp. Biol. 1938, 15, 235.

68. Bass, C.; Jones, C.M. Mosquitoes boost body armor to resist insecticide attack. Proc. Natl. Acad. Sci. USA 2016, 113, 9145-9147. [CrossRef]

69. Lilly, D.G.; Latham, S.L.; Webb, C.E.; Doggett, S.L. Cuticle Thickening in a Pyrethroid-Resistant Strain of the Common Bed Bug, Cimex lectularius L. (Hemiptera: Cimicidae). PLoS ONE 2016, 11, e0153302. [CrossRef]

70. Goyens, J.; Van Wassenbergh, S.; Dirckx, J.; Aerts, P. Cost of Flight and the Evolution of Stag Beetle Weaponry. J. R. Soc. Interface 2015, 12, 20150222. [CrossRef]

71. Schmidt-Nielsen, K. Animal Physiology: Adaptation and Environment, 5th ed.; Cambridge University Press: Cambridge, UK; New York, NY, USA, 1997; ISBN 978-0-521-57098-5.

72. Bernhardt, S.A.; Blair, C.; Sylla, M.; Bosio, C.; Black, W.C., IV. Evidence of multiple chromosomal inversions in Aedes aegypti formosus from Senegal. Insect Mol. Biol. 2009, 18, 557-569. [CrossRef]

73. Redmond, S.N.; Sharma, A.; Sharakhov, I.; Tu, Z.; Sharakhova, M.; Neafsey, D.E. Linked-read sequencing identifies abundant microinversions and introgression in the arboviral vector Aedes aegypti. BMC Biol. 2020, 18, 26. [CrossRef]

74. Fournier-Level, A.; Good, R.T.; Wilcox, S.A.; Rane, R.V.; Schiffer, M.; Chen, W.; Battlay, P.; Perry, T.; Batterham, P.; Hoffmann, A.A.; et al. The spread of resistance to imidacloprid is restricted by thermotolerance in natural populations of Drosophila melanogaster. Nat. Ecol. Evol. 2019, 3, 647-656. [CrossRef]

75. Ayala, D.; Ullastres, A.; González, J. Adaptation through chromosomal inversions in Anopheles. Front. Genet. 2014, 5. [CrossRef] [PubMed] 